\title{
Pielitis incrustante: importancia del tratamiento. Reporte de un caso
}

Montoya-Chinchilla $R,{ }^{1}$ Berrio-Campos $R,{ }^{1}$ Veas-López $A B,{ }^{2}$ Ortiz-Romero $\mathrm{MM},{ }^{3}$ García-Espona $\mathrm{C},{ }^{1}$ Moreno-Avilés $\mathrm{J}^{1}$

\section{Resumen}

ANTECEDENTES: la pielitis incrustante es una enfermedad infecciosa, difícil de diagnosticar y tratar, caracterizada por incrustaciones uroteliales de la pared del tracto urinario.

CASO CLÍNICO: hombre de 75 años de edad con síndrome mielodisplásico moderado, uropatía obstructiva bilateral secundaria a pielitis incrustante y litiasis ureteral. Después de varios meses de recibir antibióticos por vía oral, acidificantes orales e intrarrenales, el paciente falleció por sepsis urinaria e intenso deterioro inmunológico provocado por la enfermedad basal, aunque con una clara disminución de la carga litiásica.

CONCLUSIONES: el tratamiento de la pielitis incrustante es complejo y prolongado. La prescripción combinada con diferentes fármacos puede disminuir de forma importante la carga litiásica en estos pacientes.

PALABRAS CLAVE: cálculos renales, cálculos ureterales, pielitis, infecciones del tracto urinario, Corynebacterium urealyticum.

Rev Mex Urol. 2017 March;77(2):138-142.

\section{Encrusted pyelitis management: Importance of treatment. A case report}

Montoya-Chinchilla $R,{ }^{1}$ Berrio-Campos $R,{ }^{1}$ Veas-López $A B,{ }^{2}$ Ortiz-Romero MM, ${ }^{3}$ García-Espona $C^{1}{ }^{1}$ Moreno-Avilés J ${ }^{1}$

\begin{abstract}
BACKGROUND: encrusted pyelitis is an infectious disease that is difficult to both diagnose and treat. It is characterized by urothelial incrustations in the wall of the urinary tract.

CLINICAL CASE: a 75-year-old man presented with a moderate case of bilateral obstructive uropathy secondary to incrusted pyelitis and ureteral stones. After several months of triple therapy with oral antibiotic and oral and intrarenal acidifiers, the patient died due to urinary sepsis arising from intense immunologic deterioration caused by his underlying disease, albeit with a clear reduction of stone burden.
\end{abstract}

DISCUSSION: encrusted pyelitis treatment is complex and of long duration. The prescription of different drug combinations can significantly reduce the stone burden in these patients.

KEY WORDS: kidney stones, ureteral stones, pyelitis, urinary tract infections, Corynebacterium urealyticum

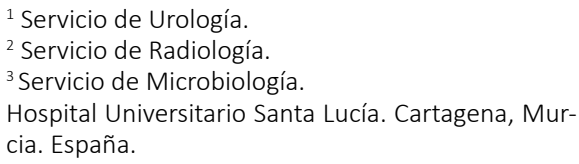

Este artículo debe citarse como Montoya-Chinchilla R, Berrio-Campos R, Veas-López $A B$, Ortiz-Romero MM, García-Espona C, MorenoAvilés J. Pielitis incrustante: importancia del tratamiento. Reporte de un caso. Reporte de un caso. Rev Mex Urol. 2017 mar;77(2):138-142 


\section{ANTECEDENTES}

La pielitis incrustante es una enfermedad infecciosa que suele afectar a pacientes inmunodeprimidos, caracterizada por incrustaciones cálcicas uroteliales, provocada por gérmenes de la especie bacteriana Corynebacterium urealyticum. ${ }^{1,2}$

El cuadro histopatológico incluye lesiones ulcero-necróticas en la mucosa urotelial, asociada con múltiples y severas incrustaciones cálcicas con importante infiltración polimorfonuclear y edema congestivo del corion.

El diagnóstico y tratamiento representa un reto para los especialistas; por tanto, es importante conocer el abordaje en estos pacientes.

\section{CASO CLÍNICO}

Hombre de 75 años de edad, con antecedente de epilepsia relacionada con síndrome mielodisplásico moderado-severo, secundario al consumo de valproato. Después de tres meses de efectuarle una resección transuretral prostática, por síntomas obstructivos severos del tracto urinario inferior (sin calcificaciones urinarias en el estudio preoperatorio), el paciente acudió al servicio de Urgencias por deterioro del estado general y fiebre. Se detectó insuficiencia renal aguda, pH alcalino de 8.5, bacteriuria severa e hidronefrosis bilateral grado III, secundaria a uropatía obstructiva litiásica bilateral ureteral proximal (Figura 1).

Se realizó derivación urinaria bilateral con nefrostomía percutánea y se indicó tratamiento para sepsis urinaria grave, con lo que se obtuvo evolución satisfactoria. Posteriormente se realizaron dos urocultivos (al ingreso e intraquirúrgico) con resultados negativos. Dada la persistencia de cuadros febriles de menos intensidad y calcificación urotelial severa de rápida aparición, se planteó efectuar un estudio de urocultivo específico para

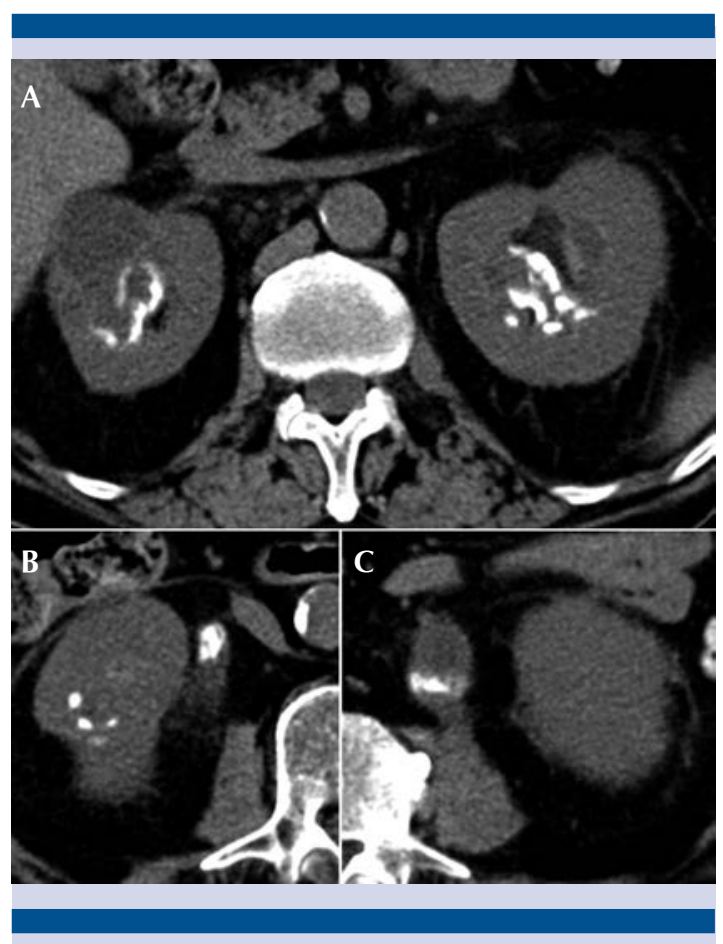

Figura 1. Calcificaciones uroteliales dispersas en ambos sistemas pielocaliciales asociadas con engrosamientos cálcicos focales (A). Litiasis ureteral proximal bilateral (B y C).

Corynebacterium urealyticum. El cultivo se realizó en agar sangre, con periodo lento de incubación (48-72 horas), en atmosfera $\mathrm{CO}_{2}$ de $10 \%$; después de este periodo se identificó el crecimiento de dicho agente infeccioso (Figura 2).

Luego de establecer el diagnóstico microbiológico se decidió prescribir, por tiempo prolongado, $100 \mathrm{mg} /$ día de doxiciclina (sensibilidad comprobada en antibiograma) y $250 \mathrm{mg} / 12 \mathrm{~h}$ de ácido acetohidroxámico por vía oral, además de irrigaciones con solución de Suby G a través de las nefrostomías (los primeros días durante la hospitalización y posteriormente en su domicilio) a dosis de $100 \mathrm{~mL} /$ día por cada una.

Para evitar presiones intrarrenales elevadas y excesivo tiempo de contacto del urotelio supe- 


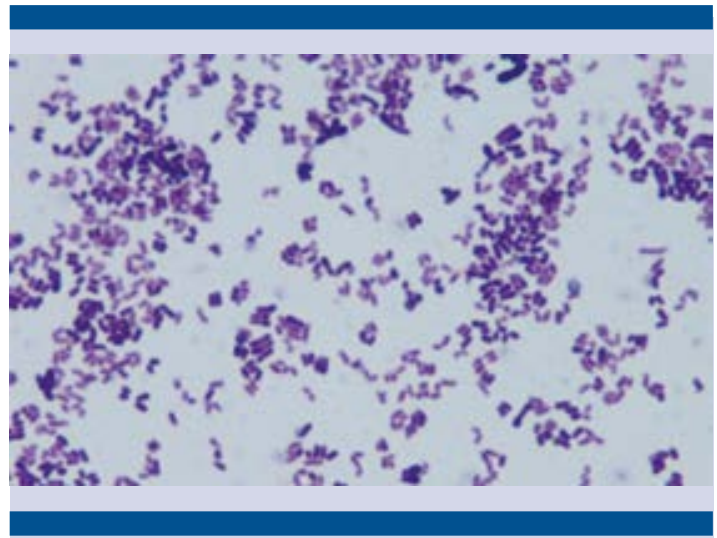

Figura 2. Bacilos grampositivos de morfología irregular, no paralelos y de bordes curvados, frecuentemente agrupados en forma de "V".

rior con la solución de Suby G, se realizó doble cateterización ureteral "doble J".

El paciente ingresó en varias ocasiones al servicio médico por sepsis urinaria, la mayor parte causadas por Klebsiella pneumoniae, cada vez con mayor resistencia a los antibióticos. En cada ingreso se observó que el síndrome mielodisplásico era más crónico, con cifras muy bajas de la serie blanca y plaquetaria, por lo que se requirió el apoyo del servicio de Hematología, quienes aplicaron tratamiento con diferentes tipos de estimuladores de eritrocitos y neutrófilos.

Después de 8 meses de tratamiento continuo desapareció la litiasis ureteral proximal, se normalizó el pH urinario y disminuyó la calcificación pielocalicial, sin observarse complicaciones locales adicionales (Figura 3). Para eliminar toda concreción calcárea se propuso efectuar ureterorrenoscopia bilateral, pero no fue posible. A pesar de varios intentos de tratamiento y trasfusiones plaquetarias, el cuadro de mielodisplasia fue cada vez más severo. Al término de 11 meses de tratamiento falleció el paciente, en su domicilio, por un nuevo evento de sepsis urinaria.
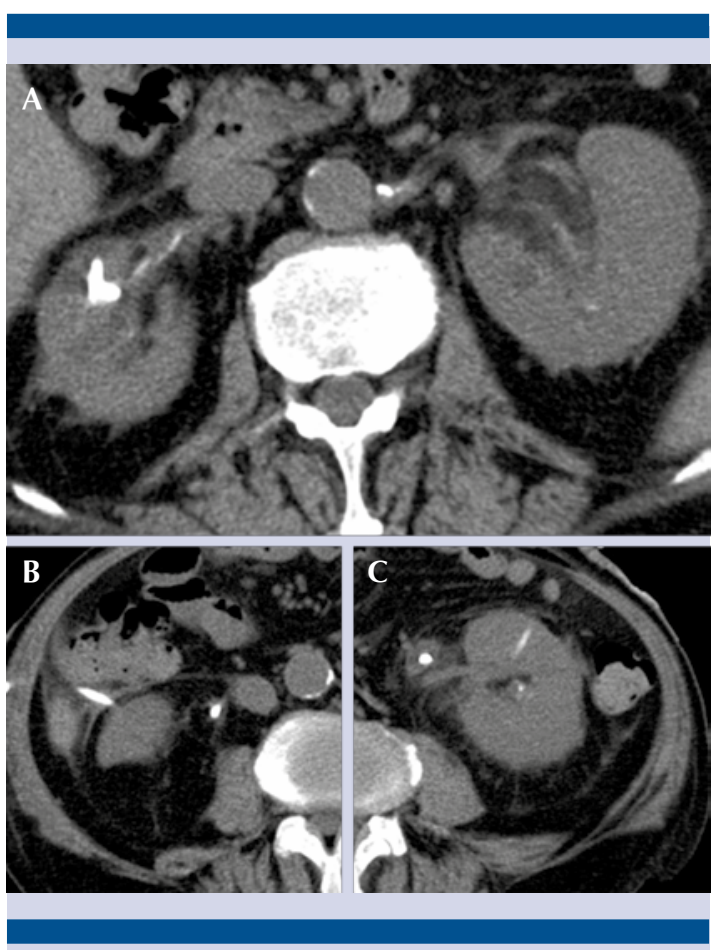

Figura 3. Marcada reducción de las calcificaciones pielocaliciales (extremo superior de catéter ureteral derecho) (A). Ausencia de litiasis ureteral proximal. Catéteres ureterales bilaterales (B y C).

\section{DISCUSIÓN}

La pielitis incrustante es una enfermedad infecciosa poco frecuente, que suele afectar a pacientes inmunodeprimidos, con algún tipo susceptibilidad de infección de las vías urinarias (antecedente de cirugía urológica, sondaje vesical, síntomas obstructivos del conducto urinario inferior, etc.). ${ }^{1}$

Corynebacterium urealyticum es el microorganismo aislado con mayor frecuencia en pacientes con pielitis incrustante. Es un bacilo grampositivo, descubierto en 1972, con fuerte actividad ureasa y catalasa positiva; ${ }^{2,3}$ suele desarrollarse en agar sangre, a lenta incubación (2-3 días), en atmosfera $\mathrm{CO}_{2}$ al $10 \%{ }^{4}$, incluso en placas $\sin$ medios específicos después de 5-6 días de cul- 
tivo. Forman colonias pequeñas, no hemolíticas, convexas, con bacilos de bordes curvados y se agrupan en formas de "V". Además, muestran elevado trofismo por el urotelio, lo que les permite alcanzar la vía urinaria superior de forma rápida y de esta manera crear un ambiente alcalino, generalmente de 7.5 o mayor, favorable para el adecuado crecimiento bacteriano, lo que resulta en la formación de cristales de carboapatita y estruvita incrustados en el urotelio. ${ }^{1}$

El cuadro clínico es inespecífico, principalmente sepsis urinaria e insuficiencia renal aguda, provocada por las calcificaciones urinarias de rápida aparición y progresión. ${ }^{5}$ La poca especificidad de los síntomas y la necesidad de cultivos específicos o de larga incubación pueden retrasar el diagnóstico diferencial o definitivo en este tipo de pacientes.

Las pruebas complementarias suelen mostrar $\mathrm{pH}$ alcalino, cristaluria, bacteriuria, insuficiencia renal aguda e incrustaciones lineales en el sistema pielocalicial con focos más o menos engrosados de calcificaciones urinarias. En estos casos, la tomografía simple representa el estudio de imagen de primera línea para establecer el diagnóstico. ${ }^{1,6}$

El tratamiento de la pielitis incrustante es complejo y de larga duración. El objetivo consiste en eliminar la litiasis y erradicar la infección bacteriana. El tratamiento incluye diversos fármacos; sin embargo, debe restablecerse el sistema inmunitario del paciente, porque sería poco efectivo e insuficiente el protocolo implementado.

Desde el punto de urológico, el tratamiento se basa en:

1. Antibióticos. Empíricamente se indica vancomicina o teicoplanina; sin embargo, el protocolo deberá ajustarse a los antibiogramas obtenidos, dada la alta resistencia antibiótica de los microorganismos. ${ }^{7}$ La duración total del tratamiento se encuentra mal definida; no obstante, debe mantenerse hasta la completa desaparición de las estructuras litiásicas.

2. Acidificación urinaria. Genera el ambiente bacteriostático necesario para el tratamiento. Pueden prescribirse agentes orales e intrarrenales. El ácido acetohidroxámico (potente inhibidor de la ureasa) puede indicarse por vía oral; ha demostrado sinergia en combinación con antibióticos. La acidificación urinaria ha conseguido la disolución de las incrustaciones en múltiples estudios; además, previene la sobresaturación de calcio intrarrenal. Aunque puede administrarse de forma crónica, se ha observado abandono del tratamiento, por efectos adversos que genera (flebitis y anemia hemolítica). La acidificación intrarrenal ofrece mejores resultados que la acidificación oral. La combinación con solución de Suby G (ácido cítrico y óxido de magnesio), de Thomas (gluconato de sodio y ácido cítrico) y DR ( $\mathrm{N}$-acetilcisteina, ácido acetohidroxámico y aztreonam) se ha prescrito para la disolución litiásica de la pielitis incrustante. Se recomienda irrigación a bajas presiones a través de nefrostomías con derivación ureteral. La posología y duración del tratamiento no están claramente definidas, aunque los pocos efectos secundarios descritos parecen posibilitar su implementación a largo plazo. ${ }^{1,5,6}$

3. Eliminación quirúrgica litiásica. La eliminación completa es extremadamente compleja, debido a la incrustación urotelial, además de provocar serias complicaciones; por tanto, debe considerarse el tratamiento individualizado. ${ }^{5}$ 


\section{REFERENCIAS}

1. Meria P, Jungers P. Encrusted pyelitis: an underdiagnosed condition? Nephrol Dial Transplant. 2000;15(7):943-5.

2. King EO. The identification of unusual gram-positive bacteria. Atlanta: Centers for Disease Control, 1972.

3. Soriano F, Ponte C, Santamaria M, et al. Corynebacterium group D2 as a cause of alkaline-encrusted cystitis: report four cases and characterization of the organism. J Clin Microbiol 1985;21:788-792.

4. Soto A, Zapardiel J, Soriano F. Evaluation of Api Coryneform system for identifying coryneform bacteria. J Clin Pathol 1994;47:756-759.
5. Hertig A, Duvic C, Chretien Y, et al. Encrusted pyelitis of native kidneys. J Am Soc Nephrol. 2000;11(6):1138-40.

6. Sánchez-Martín FM, López-Martínez JM, KanashiroAzabache A, et al. Corinebacterium urealyticum: increased incidence of infection and encrusted uropathy. Actas Urol Esp. 2016;40(2):102-7.

7. European Committee on Antimicrobial Susceptibility Testing (homepage on the internet). EUCAST breakpoints tables. [en línea]. Dirección URL: <http//www.eucast. org/clinical-breakpoints/-EUCAST:clinicalbreakpoints>. [Consulta: enero 2016].

\section{AVISO PARA LOS AUTORES}

Revista Mexicana de Urología tiene una nueva plataforma de gestión para envío de artículos. En: https://www.revisionporpares.com/index.php/RMUrol podrá inscribirse en nuestra base de datos administrada por el sistema Open Journal System (OJS) que ofrece las siguientes ventajas para los autores:

- Subir sus artículos directamente al sistema.

- Conocer, en cualquier momento, el estado de los artículos enviados, es decir, si ya fueron asignados a un revisor, aceptados con o sin cambios, o rechazados.

- Participar en el proceso editorial corrigiendo y modificando sus artículos hasta su aceptación final. 